\title{
PEMIKIRAN EKONOMI BAPAK EKONOMI ISLAM; IBNU KHALDUN
}

\author{
Choirul Huda, IAIN Walisongo Semarang
}

\begin{abstract}
Economic issues discussed by Ibn Khaldun in bis book that in section $V$. Economic motive arises because human desires are unlimited, being goods that will satisfy his needs were very limited. Therefore, to solve the economic problems must be viewed from two angles; corner power (werk, arbeid) and from the point of use. Ibn Khaldun also talks about personal business and general busines. It was described on the explanation of the terms 1 ( ma'asy and Rizqy) and the terms 2 (tamawwul and kasab). On currencies, Ibn Khaldun predicts that both will be taking place in the world's most important economy, namely: first , becoming exchanger and price measures, as the value of the business (makasib); secondly, a means of transportation, such as deviezen (qaniah); and third, an instrument deposits in banks (zakhirah). In addition to the things already mentioned above, there are still some other things discussed Ibn Khaldun relation to the economy's problems. But the bottom line is, Ibn Khaldun through his work does not already represent the most Muslim scientists in the world arena of economic thought. In fact, not in order to praise it exceeds the limit, at least he has contributed to the European renaissance.
\end{abstract}

Keywords : economy, al-Muqaddimah, private businesses, public enterprises, the currency

\section{Pendahuluan}

Dalam kehidupan sehari-hari, kita tidak dapat melepaskan diri dari berbagai persoalan ekonomi. Disadari maupun tidak, sejak manusia terlahir ke dunia ini hingga ia meninggal, setiap saat ia bersinggungan dengan persoalan ekonomi. Agama sendiri sebagai pegangan hidup bagi umat manusia di muka bumi telah banyak memberikan isyarat tentang perilaku ekonomi ini. Dorongan al-Qur'an agar manusia mencari kebahagiaan di dunia selain kebahagiaan di akherat sebagaimana yang termuat di dalam Surat al-Qashshash ayat 77 adalah salah satu contoh tentang hal itu. Dan tentu saja dorongan itu 
Pemikiran Ekonomi Bapak Ekonomi Islam; Ibnu Khaldun

masih banyak lagi tersebar dalam ayat-ayat al-Qur'an, di samping Nabi Muhammad sendiri adalah seorang pedagang yang acap kali berbicara tentang kehidupan, perdagangan dan perekonomian melalui hadits-hadits beliau.

Ekonomi, pada umumnya didefinisikan sebagai kajian tentang perilaku manusia dalam hubungannya dengan pemanfaatan sumber-sumber produktif yang langka untuk memproduksi barag-barang dan jasa-jasa serta mendistribusikannya untuk dikonsumsi. ${ }^{1}$ Atas dasar ini, kehidupan ekonomi sangat dekat dengan perilaku hidup manusia dan menarik perhatian para pemikir kontemporer untuk mengkajinya, baik ditinjau dari sisi teoritik maupun praktisnya.

Dalam lintasan sejarah umat Islam di dapati banyak sekali tokoh yang membincangkan persoalan ekonomi yang secara sosiologis turut membangun teori-teori/konsep ekonomi, seperti Abu Yusuf (w.182 H), Yahya bin Adam (w.303 H), Al-Ghozali (w.505 H), Ibnu Rusyd (w.595 H), al-Izz bin 'Abdis Salam (w.660 H), al-Farabi (w.339H), Ibnu Taymiyah (w.728 H), Ibnu Khaldun (w.808 H), al-Maqrizi (w.845 H), dan lain-lain.

Namun demikian, agar lebih tepat dalam memotret sejarah sosial terbentuknya teori ekonomi tersebut, artikel ini akan membidik salah satu di antara para pemikir muslim yang telah disebutkan, yaitu Ibnu Khaldun. Pilihan terhadap Ibnu Khaldun dimaksudkan untuk memberikan gambaran bahwa dalam kehidupan sosial tertentu, akan memunculkan corak pemikiran tertentu pula (dalam hal ini pemikitan tentang ekonomi).

Selain itu, Ibnu Khaldun merupakan tokoh pemikir yang mahir dalam berbagai bidang kajian, baik politik, sosial, filsafat, sejarah, maupun ekonomi itu sendiri. Sehingga tidak berlebihan jika pemilihan nama Ibnu Khaldun sebagai salah satu pencetus teori ekonomi sangatlah layak dikemukakan. Tentu saja hal ini akan diimbangi dengan kausa-kausa Ibnu Khaldun yang monumental, yang dipadukan dengan sejarah sosial kehidupan yang ia alami.

${ }^{1}$ Dr. Mustaq Ahmad, Etika Bisnis dalam Islam, (Jakarta: Pustaka al-Kautsar,2001), hlm. 4. 


\section{Biografi Ibnu Khaldun}

\section{Seputar Kelahiran dan keluarga Ibnu Khaldun}

Nama lengkapnya adalah Abd al-Rabman bin Mubammad bin Khaldun al-Hadrawi, ${ }^{2}$ dikenal dengan panggilan Waliyuddin Abu Zaid, Qadi al-Qudat. Ia lahir tahun $732 \mathrm{H}$ di Tunis ${ }^{3}$. Ia bermazhab Maliki, Muhadist al-Hafidz, pakar ushul fiqh, sejarawan, pelancong, penulis dan sastrawan. ${ }^{4}$ Saat kecil ia biasa dipanggil dengan nama Abdurrahman. Sedangkan Ibnu Zaid adalah panggilan keluarganya. Ia bergelar waliyudin dan nama populernya adalah Ibnu Khaldun. ${ }^{5}$

Gelar waliyudin merupakan gelar yang diberikan orang sewaktu Ibnu Khaldun memangku jabatan hakim (qadli) di Mesir. Sebutan 'alamah didepan namanya menunjukkan bahwa pemakai gelar tersebut merupakan orang yang mempunyai gelar kesarjanaan tertinggi, sebagaimana gelar-gelar yang lain, seperti Rais, al-Hajib, al-Shadrul, al-Kabir, al-Faqih, al-Jalil dan Imamul A'immah, Jamal al-Islam wa al-Muslimin. ${ }^{6}$ Mengenai tambahan nama belakangnya, al-Maliki, ini dihubungkan dengan imam mazhab yang dianutnya dalam ilmu fiqh, yaitu mazhab Imam Malik bin Anas. ${ }^{7}$

Nenek moyangnya berasal dari Hadramaut yang kemudian berimigrasi ke Seville (Spanyol) pada abad ke-8 setelah semenanjung itu dikuasai Arab muslim. Keluarga yang dikenal pro Umayah ini selama berabad-abad menduduki posisi tinggi dalam politik di Spanyol, sampai akhirnya hijrah ke Maroko beberapa tahun sebelum Seville jatuh ke tangan

${ }^{2}$ Dalam buku The Encyclopedia of Islam, disebutkan bahwa nama lengkap Ibnu Khaldun adalah Waliudin Abdurrahman Abu Zaid ibn Muhammad ibn Abu Bakar Muhammad ibn al-Hasan ibn Muhammad ibn Jabir ibn Muhammad ibn Ibrahim ibn Abdurrahman ibn Khalild (Bernard Lewis, et. al., The Encyclopedia of Islam, vol. VIII, (Leiden: E.J. Brill \& London: Luzac\&Co,1971), hlm. 825)

3 Tepatnya, Ibnu Khaldun lahir pada tanggal 1 Ramadhan $732 \mathrm{H}$ atau bertepatan dengan tanggal 27 Mei $13332 \mathrm{M}$ di Tunisia (Afrika Utara).

4 Abdullah Mustafa al-Maraghi, Fath al-Mubin fi Tabaqat al-Ushuliyyin, terj. Husein Muhammad, (Yogyakarta: LKPSM, 2001), hlm. 287.

${ }^{5}$ Ali Audah, Ibnu Khaldun, Sebuah Pengantar, (Jakarta: Pustaka Pelajar, 1982), hlm. 26.

${ }^{6} \mathrm{Ibid}, \mathrm{hlm} .27$.

7 Ali Abdul Wakhid Wafi, Ibnu Khaldun; Riwayat dan Karyanya, Jakarta: PT. Grafika Pers, 1985), hlm. 27.

Volume IV/Edisi 1/Mei 2013 
Pemikiran Ekonomi Bapak Ekonomi Islam; Ibnu Khaldun

Kristen pada 1248 M. Setelah itu mereka menetap di Tunisia. Di kota ini mereka dihormati oleh pihak istana, diberi tanah milik dinasti Hafsiah. ${ }^{8}$

Latar belakang keluarga dari kelas atas ini rupanya menjadi salah satu faktor penting yang kemudian mewarnai karir hidup Ibnu Khaldun dalam politik sebelum ia terjun sepenuhnya ke dunia ilmu. Otak cerdas yang dimilikinya jelas turut bertanggung jawab mengapa ia tidak puas bila tetap berada di bawah. Orientasi ke atas inilah yang mendorongnya untuk terlibat dalam berbagai intrik politik yang melelahkan di Afrika Utara dan Spanyol.

\section{Perjalanan Studi dan Karya-Karya Ibnu Khaldun}

Ibnu Khaldun dibesarkan dalam keluarga ulama dan terkemuka. Dari ayahnya ia belajar ilmu qiro'at. Sementara ilmu hadits, bahasa Arab dan figh diperoleh dari para gurunya, Abu al-Abbas al-Qassar dan Muhammad bin Jabir al-Rawi. Ia juga belajar kepada Ibn 'Abd al-Salam, Abu Abdullah bin Haidarah, al-Sibti dan Ibnu 'Abd al-Muhaimin. Kemudian memperoleh ijazah hadits dari Abu al-Abbas al-Zawawi, Abu Abdullah al-Iyli, Abu Abdullab Mmubammad, dan lain-lain. Ia pernah mengunjungi Andalusia dan Maroko. Di kedua negara itu ia sempat menimba ilmu dari para ulamanya, antara lain Abu Abdullah Mubammad al-Muqri, Abu al-Qosim Muhammad bin Mubammad al-Burij, Abu al-Qasim al-Syarif al-Sibti, dan lainlain. Kemudian mengunjungi Persia, Granada, dan Tilimsin. ${ }^{9}$

Banyak tokoh dan ulama yang menjadi muridnya. Mereka antara lain Ibnu Maræuq al-Hafidz, al-Damamini, al-Busili, al-Bisati Ibnu Ammar, Ibnu Hajar, dan lain-lain. ${ }^{10}$

Dalam usia muda Ibnu Khaldun sudah menguasai beberapa disiplin ilmu Islam klasik, termasuk 'ulum aqliyah (ilmu-ilmu kefilsafatan, tasawuf dan metafisika). Di bidang hukum, ia mengikuti mazhab Maliki. Di samping itu semua, ia juga tertarik pada ilmu politik, sejarah, ekonomi,

\footnotetext{
8 Ahmad Syafi'I Ma'arif, Ibnu Khaldun dalam Pandangan Penulis Barat dan Timur, (Jakarta: Gema Insani Press, 1996), hlm. 12.

${ }^{9}$ Abdullah Mustafa al-Maraghi, op.cit., hlm. 287.

${ }^{10}$ Ibid.
} 
geografi, dan lain-lain. ${ }^{11}$ Otaknya memang tidak puas dengan satu dua disiplin ilmu saja. Di sinilah terletak kekuatan dan sekaligus kelemahan Ibnu Khaldun. Pengetahuannya begitu luas dan berfariasi ibarat sebuah ensiklopedi. Namun dari catatan sejarah, ia tidak dikenal sebagai seorang yang sangat menguasai satu bidang disiplin.

Karya-karya Ibnu Khaldun, termasuk karya-karya yang monumental. Ibnu Khaldun menulis banyak buku, antara lain; Syarh alBurdah, sejumlah ringkasan atas buku-buku karya Ibnu Rusyd, sebuah catatan atas buku Mantiq, ringkasan (mukhtasor) kitab al-Mahsul karya Fakhr al-Din al-Razi (Ushul Fiqh), sebuah buku lain tentang matematika, sebuah buku lain lagi tentang ushul fiqh dan buku sejarah yang sangat dikenal luas. Buku sejarah tersebut berjudul Al-Ibar wa Diwan al-Mubtada' wa al-Khabar fi Tarikh al-Arab wa al-Ajam wa al-Barbar. Ibnu Khaldun melalui buku ini benar-benar menunjukkan penguasaannya atas sejarah dan berbagai bidang ilmu pengetahuan. ${ }^{12}$ Di samping kitab tersebut, kitab al-Muqoddimah Ibnu Khaldun merupakan karya monumental yang mengundang para pakar untuk meneliti dan mengkajinya.

Tokoh ini meninggal dunia secara mendadak di Kairo pada tahun $807 \mathrm{H}$ dan dimakamkan di kuburan kaum sufi di luar Bab al-Nasr. ${ }^{13}$

\section{Karir Hidup yang Penuh Gejolak}

Masa kecil dan awal masa mudanya tidak diketahui secara rinci. Namun sebagai bagian dari keuarga elit, Ibnu Khaldun telah aktif dalam kegiatan intelektual di kota kelahirannya, di samping mengikuti dari dekat kehidupan politik. Neneknya pernah menjabat menteri keuangan Tunisia, sementara ayahnya sendiri adalah seorang administrator dan perwira militer, meskipun kemudian mengundurkan diri agat dapat memusatkan perhatian kepada dunia ilmu; hukum, theology dan sastra, sampai ia wafat

\footnotetext{
${ }^{11}$ Baca secara lengkap di Muhsin Mahdi, Ibnu Khaldun's Philosophy of History, (Chicago: The University of Chicago Press, 1971), hlm. 27-29.

12 Abdullah Mustafa al-Maraghi, loc.cit

${ }^{13}$ Ibid.
} 
Pemikiran Ekonomi Bapak Ekonomi Islam; Ibnu Khaldun

karena penyakit menular yang terkenal dengan sebutan the black death pada $1349,{ }^{14}$ pada saat Ibnu Khaldun berusia 17 tahun.

Jauh sebelum menulis di Al-Muqaddimah, Ibnu Khaldun, sebagaimana telah disinggung di atas, telah terlibat dalam intrik politik. Itu terjadi bahkan sebelum berusia 20 tahun. Kenyataan ini menjelaskan kepada kita bahwa ia sejak awal sudah mengamati bagamana kiprah orang dalam politik. Persaingan keras, saling menjatuhkan, saling menghancurkan adalah fenomena yang biasa berlaku. Politik yang disaksikannya adalah politik adu kekuatan, tidak peduli bingkai moral telah diinjak-injak.

Yang menarik adalah bahwa Ibnu Khaldun muda seakan menikmati iklim semacam itu. Dinasti-dinasti kecil bersaing satu sama lain sebagai pertanda dari proses membusuknya imperium Arab muslim di Afrika Utara. Pengalaman terusirnya umat Islam dari Spanyol yang sebelumnya mereka kuasai selama tujuh abad sudah tidak lagi dapat mengajar mereka untuk berhenti berkelahi.

Dinasti-dinasti kecil yang saling bersaing itu adalah; Banu Hafsiah di Tunisia, al-Marini di Maroko, al-Mahdi di Bijjaya, Banu Nasr di Granada, dan pusat-pusat kekuasaan kecil lainnya. Inilah di antara bentuk perpecahan yang sangat parah di kalangan penguasa-penguasa Arab Muslim, sementara kerajaan-kerajan Kristen Spanyol bergerak ke arah kutub yang berbeda; melakukan konsolidasi secara efektif menuju persatuan dan kekompakan. Situasinya dengan baik digambarkan oleh alFaruqi:

"Ini adalah abad tentang intrik politik, tentang suksesi kekuasaan yang cepat dan keras antara negara-negara muslim yang keadaan umumnya dalam kejatuhan dan kehancuran. Muslim berkomplot jahat terhadap satu sama lain, mengalihkan kesetiaannya dari pemerintahan dan penguasa yang satu kepada yang lain demi pemenuhan kepentingan pribadi. Ibnu Khaldun sepenuhnya sesuai dengan lingkungan semacam itu, seakan ia dilahirkan bukan hanya di dalamnya, tetapi untuk keadaan semacam itu."15

\footnotetext{
${ }^{14}$ Bernard Lewis, op. cit., hlm. 825

15 Lih. Ismail R. Al-Faruqi, The Cultural Atlas of Islam, (New York; Mac Millan Publicing Company, 1986), hlm. 310
} 
Demi promosi diri ke posisi yang lebih atas, Ibnu Khaldun berganti-ganti tuan setelah satu persatu dikhianatinya. Dalam usia 20 tahun, Ibnu Kladun telah diangkat menjadi sekretaris Sultan Abu Inan dari Fez, Maroko. Dia menetap di sana antara 1354 M sampai 1362 M. Namun pada awal $1357 \mathrm{Abu}$ Inan mencurigainya sebagai pengkhianat. Lalu ia dipenjarakan selama 21 bulan. Dan baru dibebaskan setelah sultan wafat. Abu Inan digantikan oleh Abu Salim yang kemudian merehabilitasi kedudukan Ibnu Khaldun pada berbagai posisi pnting kerajaan. Namun keadaan seperti itu tidak bertahan lama. Iklim politik yang penuh intrik telah menyebabkan terbunuhnya Abu Salim pada 1361 M dalam suatu pemberontakan sipil dan militer. Suasana di Fez makin tidak menentu. Ibnu Khaldun di samping masih dicurigai, perasaannnya sudah ingin meninggalkan Afrika Utara demi karirnya sebagai politikus dan pengamat. Akhirnya ia berangkat ke Spanyol dan sampai di Granada pada 26 Desember 1362 M. ${ }^{16}$

Sebagai sekretaris Sultan Abu Salim, Ibnu Khaldun diterima dengan penghormatan di istana Raja Muhammad V di Granada. Raja ini didampingi oleh seorang wazir (perdana menteri) Ibn al-Khatib, seorang penulis dan sarjana terkemuka. Ibnu Khaldun telah menjalin persahabatan dengan politikus dan penulis ini. Demikian tingginya kepercayaan raja kepada pendatang ini dibuktikan dengan pengutusan Ibnu Khaldun pada tahun 1364 M sebagai duta ke istana Raja Pedri el-Cruel, raja Kristen Castilla di Seville. Seville punya makna tersendiri bagi Ibnu Khaldun. Di kota inilah nenek moyangnya tinggal selama berabad-abad. Sebagai seorang diplomat, Ibnu Khadun ditugaskan untuk mengadakan perjanjian damai antara Granada dan Seville. ${ }^{17}$

Untuk sementara Ibnu Khaldun mulai merasa tenang di Granada, sebuah kota yang penuh warna warni. Terpikir juga olehnya untuk membawa keluarganya ke kota itu lantaran suasana dirasakannya aman. Namun rintangan selalu saja muncul. Tidak lama kemudian suasana cerah telah berubah menjadi mendung. Terkilas kecemburuan Ibn al-Khatib

${ }^{16}$ Ibid.

${ }^{17}$ Lih. Syafi'i Ma'arif, op.cCit., hlm. 14 
Pemikiran Ekonomi Bapak Ekonomi Islam; Ibnu Khaldun

kepadanya lantaran radius pengaruh Ibnu Khaldun di istana semakin meluas. ${ }^{18}$

Sebagai seorang yang sudah kenyang hidup dalam suasana intrik dan kecemburuan politik, Ibnu Khaldun cukup sadar untuk tidak terlibat dalam konflik terbuka dengan al-Khatib. Kemampuan sastra saingannya ini tetap diakui dan dihormati Ibnu Khaldun, sekalipun kontrak pribadi antara keduanya telah terganggu. Sampai saat terbunuhnya al-Khatib di Fez pada 1374 M, Ibnu Khaldin hanya sempat sekali berjumpa dengannya, tidak lama sebelum berlakunya peristiwa naas itu. ${ }^{19}$

Sesudah peristiwa itu, Ibnu Kaaldun bertekad menjauh, meskipun tawaran-tawaran kedudukan tetap mengalir disodorkan kepadanya. Tawaran pertama adalah dari Abu Abdullah, penguasa Bougie, untuk menjadi perdana menteri. Sesudahnya Ibnu Khaldun menjadi pembantu Raja Abul Abbas, sampai pada akhirnya ia menolak lagi menerima tawarantawaran jabatan tersebut. Hal itu setelah lama ia berkecimpung di dunia yang meresahkan tersebut.

Penolakan di atas tampaknya karena Ibnu Khaldun sudah jenuh dan lelah terlibat dalam politik yang tidak pernah stabil dan tenang itu. Naluri kesarjanaanya telah memaksanya untuk menjauh dari kehidupan politik yang penuh gejolak dan kekerasan. Pengalamannya sebagai utusan raja-raja lokal untuk merebut kesetiaan suku-suku Badwi di Afrika Utara menjadi bahan penting baginya untuk menyusun tesis-tesisnya dalam alMuqaddimah. Dalam pengembaraan ekspedisinya untuk membujuk suku Dawawidah agar berpihak kepada Abu Hammu melawan Abul Abbas, Ibnu Khaldun akhirnya benar-benar memutuskan untuk meninggalkan panggung poitik. Dia mendapat perlindungan di kalangan Banu Arif, yaitu di istana Qal'at ibn Salamah. Dalam otobiografinya yang dikutip Toynbee, Ibnu Khaldun menulis:

"Kemudian saya mengukuhkan diri saya bersama keluarga di Qal'at ibn Salamah, seuah istana yang terletak di Negeri Banu Tajin yang diperoleh dari sultan untuk Suku Dawawiyah dalam bentuk hak feudal. Saya tinggal di Istana selama empat tahun, sepenuhnya

${ }^{18}$ Ibid., hlm 15

${ }^{19}$ Ibid. 
bebas dari kesusahan dan dari huru hara urusan umum dan di sanalah saya mulai menyusun karya saya - sejarah universal. Dalam pengunduran diri inilah saya merampungkan al-Muqaddimah, sebuah karya yag seluruhnya orisinal dalam perencanaannya dan yang saya ramu dari hasil penelitian luas yang terbaik. Sewaktu saya tinggal di Qal'at ibn Salamah, saya menempati sederetan kamar yang luas dan kuat yang dulunya cukup lama dibangun oleh $\mathrm{Abu}$ Bakr ibn Arif. Selama menetap yang cukup lama di istana ini, saya melupakan sepenuhnya kerajaan-kerajaan di Maghrib dan Tlemcen serta tidak memikirkan apa-apa kecuali karya yang sekarang ini."’20

Awal musim dingin, pada 1378 M, Ibnu Khaldun meninggalkan Qal'at ibn Salmah menuju Tunisia, negeri kelahirannya. Dalam perjalanan ia bertemu dengan sultan Abul Abbas, penguasa yang dulu pernah dikhianatinya. Sultan ini tampaknya telah memaafkannya, hingga Ibnu Khaldun sempat menikmati masa tenang di Tunisia. Namun masa tenang ini ternyata tidak berumur panjang karena beberapa temannya telah melakukan intrik terhadapnya. Tambah lagi sultan memerintahkan untuk menyertainya dalam memerangi pemberontakan. Perintah ini dinilai Ibnu Khaldun sangat berbahaya. Oleh sebab itu, dari pada turut, Ibnu Khaldun memutuskan untuk menunaikan ibadah haji saja. Ditinggalkannyalah Tunisia pada 1382 M menuju Kota Iskandaria, Mesir dan diputuskannya untuk menyinggahi Kairo sebelum akhirnya ke Mekkah. ${ }^{21}$ Dan di Kairo, ia diangkat menjadi guru serta qadhi dari Mazhab Maliki yang ia jalani dengan adil. 22

Tahun $1384 \mathrm{M}$ ia mengundurkan diri sebagai qadhi setelah mendapat berita bahwa keluarganya, yang dalam perjalanan dari Tunisia untuk menyertainya di Kairo telah menjadi korban kecelakaan kapal dekat Iskandaria. Kemudian Ibnu Khaldun diangkat oleh Sultan Barquq menjadi professor yurisprudensi pada Kolej Zahiriah Mesir. Baru pada tahun 1387 hlm. 325-326.

20 A.J. Toynbee, A Study of History, 12 Jilid, (London: Oxford Univercity Press, 1945, III),

${ }^{21}$ Fuad Baali, Society, State, and Urbanism; Ibnu Khaldun's Sociological Thought, (New York: State University of New York Press, 1988), hlm. 2.

${ }^{22}$ Ibid. 
Pemikiran Ekonomi Bapak Ekonomi Islam; Ibnu Khaldun

$\mathrm{M}$ ia mempunyai kesempatan untuk menunaikan ibadah haji, setelah tertunda beberapa tahun. Sepulang dari Mekkah, Ibnu Khaldun diangkat menjadi presiden institute Baybars di Mesir, suatu kedudukan yang harus segera dilepaskannya karena ia bersama qadhi lain megeluarkan pernyataan melawan Sultan Barquq.

Pada 1389 M, Ibnu Khaldun diangkat lagi untuk kedua kalinya menjadi qadhi dari Mazhab Maliki setelah Sultan Faraj, putera Barquq. Pada masa ini ia sempat mengunjungi Palestina. ${ }^{23}$ Peristiwa penting lain yang dialami Ibnu Khaldun selama di Mesir - dan ini merupakan peristiwa sangat historis baginya - ialah pertemuannya dengan timur (Tamerlane), sang penakluk.

\section{Pemikiran Ekonomi Ibnu Khaldun}

Salah satu karya fenomenal Ibnu Khaldun adalah Kitab Al-Muqaddimah, yang selesai penulisannya pada Nopember 1377. Sebuah kitab yang sangat menakjubkan, karena isinya mencakup berbagai aspek ilmu dan kehidupan manusia pada ketika itu. Al-Muqaddimah secara harfiah bararti 'pembukaan' atau 'introduksi' dan merupakan jilid pembuka dari tujuh jilid tulisan sejarah. Al-Muqaddimah mencoba untuk menjelaskan prinsip-prinsip yang menentukan kebangkitan dan keruntuhan dinasti yang berkuasa (daulah) dan peradaban ('umran). Tetapi bukan hanya itu saja yang dibahas. Al-Muqaddimah juga berisi diskusi ekonomi, sosiologi dan ilmu politik, yang merupakan kontribusi orisinil Ibnu Khaldun untuk cabang-cabang ilmu tersebut. Ibnu Khaldun juga layak mendapatkan penghargaan atas formula dan ekspresinya yang lebih jelas dan elegan dari hasil karya pendahulunya atau hasil karya ilmuwan yang sejaman dengannya. Melahirkan karya Al-Muqaddimah menjadikan Ibnu Khaldun sebagai seorang genius polymath (jenius dalam berbagai bakat) dan seorang renaissance man yang menguasai banyak bidang ilmu. Di dalam kitab ini, Ibnu Khaldun membincangkan berbagai topik seperti sejarah, geografi, matematik, agama, sistem kerajaan, sistem ekonomi, sistem pendidikan dan lain-lain.

${ }^{23}$ Ibid., hlm. 3 
Jika orang biasa hendak mencoba menulis mengenai semua bidang ini, bisa jadi penulisannya itu akan berbentuk dasar-dasarnya saja, karena tidak mudah untuk dapat memahami kesemua bidang tersebut dengan mendalam. Tapi Ibnu Khaldun merupakan seorang "master of all trades" yang jarang-jarang dijumpai dalam sejarah manusia. Ia dapat mengupas setiap topik tersebut dengan mendalam, dan memahami serta menyampaikan isu-isu yang kritikal dalam setiap disiplin ilmu tersebut. Memang amat mengagumkan apabila kita membaca Al-Muqaddimah dan mendapati bahwa isinya amat modern, setengah kandungannya masih relevan dengan dunia masa kini, meskipun kitab itu dikarang pada abad ke 14 .

Berikut ini diuraikan beberapa pemikiran ekonomi Ibnu Khaldun yang dalam lintasan sejarah perekonomian dunia dapat disejajarkan dengan pemikiran para tokoh ekonom modern. Wawasan Ibnu Khaldun terhadap beberapa prinsip-prinsip ekonomi sangat dalam dan jauh kedepan sehingga sejumlah teori yang dikemukakannya hampir enam abad yang lalu sampai sekarang tidak diragukan merupakan perintis dari beberapa formula teori modern.

\section{Persoalan Ekonomi}

Soal-soal ekonomi ini dibicarakan oleh Ibnu Khaldun di dalam bukunya "Al-Muqaddimah", bagian ke V. Motif ekonomi timbul karena hasrat manusia yang tidak terbatas, sedang barang-barang yang akan memuaskan kebutuhannya itu sangat terbatas. ${ }^{24}$ Sebab itu memecahkan soal-soal ekonomi haruslah dipandang dari dua sudut; sudut tenaga (werk, arbeid) dan dari sudut penggunaannya.

Adapun dari sudut tenaga terbagi kepada:

a. Tenaga untuk mengerjakan barang-barang (objekt) untuk memenuhi kebutuhannya sendiri (subjekt), dinamakan “ma'asy" (penghidupan).

b. Tenaga untuk mengerjakan barang-barang yang memenuhi kebutuhan orang banyak (Massaal subjektif), dinamakan "tamawwul' (perusahaan). ${ }^{25}$

${ }^{24}$ Abdurrahman Ibnu Khaldun, Muqaddimah Ibn Khaldun, (Beirut: Dar al-Fikr, tth), hlm. 380.

25 Ibid. 
Pembagian yang seperti ini didasarkannya kepada beberapa perkara yang terpakai di dalam kitab suci al-Qur'an. Misalnya perkataan "Tesyah" dalam Surat al-Haqqah ayat $21^{26}$ dan al-Qari'ah ayat 727; kata "ma'asy" di dalam Surat al-Naba ayat 1128; perkataan "ma'ayisy" di dalam surat al-A'raf ayat $10^{29}$, Surat al-Hijr ayat $20^{30}$; kemudian perkataan "ma'iesyah" dalam Surat Taha ayat $124^{31}$, Surat al-Qashshash ayat 5832, dan Surat al-Zukhruf ayat 32.33 Semua perkataan itu digunakan Allah sebagai istilah untuk menunjukkan perlunya tenaga manusia untuk mencukupkan kebutuhan hidupnya. Jika tenaganya digunakan untuk kebutuhan orang banyak, tidaklah dinamakan "ma'asy" atau "ma'iesyab", melainkan berubahlah sifatnya menjadi suatu perusahaan.

Adapun dari jurusan kegunaannya, dapatlah dibagi menjadi 2 hal:

a. Kegunaan barang-barang yang dihasilkan itu hanyalah untuk kepentingannya sendiri, dinamakan "rizqy" (tersebut 55 kali dalam alQur'an dengan 77 kata-kata yang sama).

b. Kegunaannya untuk kepentingan orang banyak, sedang kepentingan orang yang mengerjakan tidaklah menjadi tujuan utama. Hal ini dinamakan "kasab" (tersebut 67 kali dalam al-Qur'an). ${ }^{34}$

\footnotetext{
26 Artinya: "Maka orang itu berada dalam kehidupan yang diridhai."

27 Artinya: "Maka dia berada dalam kehidupan yang memuaskan."

28 Artinya: "Dan kami jadikan siang untuk mencari penghidupan."

${ }^{29}$ Artinya: "Sesunggubnya Kami telah menempatkan kamu sekalian di muka bumi dan Kami adakan bagimu di muka bumi itu (sumber) penghidupan. Amat sedikitlah kamu bersyukur."

30 Artinya: "Dan Kami telah menjadikan untukmu di bumi keperluan-keperluan hidup, dan (Kami menciptakan pula) mabluk-mabluk yang kamu sekali-kali bukan pemberi riqki kepadanya."

31 Artinya: "Dan barang siapa berpaling dari peringatan-Ku, maka seseunggubnya baginya penghidupan yang sempit, Dan Kami akan menghimpunnya pada hari kiamat dalam keadaan buta.”

32 Artinya: "Dan berapa banyaknya (penduduk) negeri yang telah Kami binasakan, yang sudah bersenang-senang dalam kehidupannya; maka itulah tempat kediaman mereka yang tiada didiami (lagi) sesudah mereka, kecuali sebagian kecil. Dan Kami adalab pewaris(nya)."

33 Artinya: "Apakah mereka yang membagi-bagi rahmat Tuhanmu? Kami telah menentukan antara mereka penghidupan mereka dalam kehidupan dunia, dan Kami telah meninggikan sebagian mereka atas sebagian yang lain beberapa derajat, agar sebagian mereka dapat mengambil manfaat dari sebagian yang lain. Dan rabmat Tubanmu lebih baik dari apa yang merek a kumpulkan."

${ }^{34}$ Abdurrahman Ibn Khaldun, op. cit., hlm. 381.
} 


\section{Usaha Pribadi dan Perusahaan Umum}

Pembagian ini ternyata juga di dalam kalimat-kalimat yang dipakai oleh Allah. Di dalam Surat Hud ayat 6,35 Allah memakai perkataan "Rizqy" bagi segala mahluk yang melata di bumi. Dan di dalam ayat lain Allah mewajibkan bagi tiap-tiap diri untuk mencari rizki. Adapun perkataan "kasab" tidaklah boleh dipakai sedemikian. Di dalam Surat al-Baqarah ayat 141,36 Allah menggunakan perkataan "kasab" bagi usaha suatu umat, bangsa.

Kemudian pula dalam Surat al-Rum ayat 41,37 Allah menegaskan bahwa dunia dipenuhi oleh kebinasaan dan kehancuran di daratan dan di lautan, karena perebutan dan persaingan ekonomi (kasab) antara manusia. Hal ini dengan jelas diuraikan oleh Ibn Khaldun, sebagai bagian dari proses ekonomi yang berjalan seiring dengan kehidupan umat manusia. ${ }^{38}$

Bagian ke-1 dari kedua sudut itu (ma'asy dan rizgy) hanyalah diperuntukkan bagi kebutuhan diri sendiri, sebagaimana halnya ekonomi di jaman primitif dahulu. Orang bertani, atau lebih tegasnya bercocok tanam, tenaganya bekerja dan hasilnya yang diharapkan dari pekerjaannya hanyalah semata-mata untuk memenuhi kebutuhannya serumah tangga. Pada masa itu, kalaupun ada perdagangan hanyalah dijalankan secara tukar menukar (natural wirschaft) antara orang-orang yang membutuhkan barang-barang.

Tetapi bagian kedua dari kedua sudut itu (tamawnul dan kasab) sudah merupakan usaha ekonomi. Baik tenaga yang dipakai maupun hasil yang diharapkan. Bukanlah lagi kebutuhan sendiri yang menjadi soal, tetapi pokok pertimbangan diletakkan pada kepentingan orang banyak yang memerlukan barang itu. Bagi pengusaha, bukan barang-barang itu yang diperlukan, tetapi nilai dari pekerjaan atau barang-barang yang dikerjakannya itu. Dalam bagian ini, ekonomi sudah menginjak pada jaman

\footnotetext{
35 Artinya: "Dan tidak ada suatu binatang melata di bumi melainkan Allah-lah yang memberi rizkinya, dan Dia mengetahui tempat penyimpanannya, semuanya tertulis dalam kitab yang nyata (Lauh Mahfuzh)."

36 Artinya: "Itulah umat yang telah lalu; baginya apa yang diusahakannya dan bagimu apa yang kamu usahakan; dan kamu tidak akan diminta pertanggungan jawab tentang apa yang mereka kerjakan."

${ }^{37}$ Artinya: "Telah timbul kerusakan di darat dan di laut disebabkan perbuatan tangan manusia supaya Allah merasakan kepadanya sebagian dari (akibat) perbuatannya, agar mereka kembali (ke jalan yang benar)."

38 Abdurrahman Ibn Khaldun, Loc. cit.
} 
Pemikiran Ekonomi Bapak Ekonomi Islam; Ibnu Khaldun

modern, bukan lagi tukar menukar barang, tetapi berjual beli atau seumpamanya.

\section{Mata Uang Memegang Peranan Penting}

Ibnu Khaldun hidup di jaman di mana mata uang sudah menjadi alat penghargaan. Pada masa itu ia sudah membicarakan kemungkinan yang bakal terjadi tentang kedudukan yang selanjutnya dari mata uang. Dia menulis sebagai berikut:

"Sesudah demikian, Allah telah menjadikan pula dua barang galian yang berharga, ialah emas dan perak menjadi bernilai di dalam perhubungan ekonomi. Keduanya menurut kebiasaan menjadi alat perhubungan dan alat simpanan bagi penduduk dunia. Jika terjadi alat perhubungan dengan yang lainnya pada beberapa waktu, maka tujuan yang utama tetap untuk memiliki kedua benda itu di dalam peredaran harga-harga pasar, karena keduanya terjauh dari pasar itu"39

Akhirnya Ibnu Khaldun meramalkan bahwa kedua barang galian ini nanti akan mengambil tempat yang terpenting di dalam dunia perekonomian, ialah melayani tiga kepentingan, yaitu: pertama, menjadi alat penukar dan pengukur harga, sebagai nilai usaha (makasib); kedua, menjadi alat perhubungan, seperti deviezen (qaniab); dan ketiga, menjadi alat simpanan di dalam bank-bank (zakhirah). ${ }^{40}$

Inilah analisa Ibnu Khaldun sewaktu emas dan perak baru merupakan dinar dan dirham. Dia sudah mengetahui bahwa dengan secepatnya dunia akan meninggalkan zaman natural wirschift (tukar menukar barang), berpindah kepada jaman modern yang lebih terkenal dengan "geld wirschift' (jual beli dengan perantaraan uang). Dalam jaman baru itu, emas dan perak akan menempati tempatnya "ukuran nilai" (standaard). Mungkin ada waktunya juga harga itu diganti dengan uang kertas, sebagaiman yang

39 Zainal Abidin Ahmad, Dasar-Dasar Ekonomi Islam, (Jakarta: Bulan Bintang, 1979), hlm. 310.

40 Abdurrahman Ibn Khaldun, loc. cit. 
terjadi pada jaman kita ini. Tetapi tujuan yang sebenarnya seperti keterangan Ibnu Khaldun tetap emas dan perak. Tiap-tiap uang kertas yang dicetak mesti ada jaminan emas atau perak di dalam bank.

Sebagai contoh riel adalah seperti apa yang pernah dikatakan oleh Robert G. Rodkey, bahwa bank deposit yang pertama ada di kota-kota Itali, yang dimulai pada permulaan jaman Renaissance pada abad 15, yaitu berabad-abad di belakang jaman tengah Islam. ${ }^{41}$

\section{Soal-Soal Ekonomi dalam 33 Pasal}

Uraian selanjutnya tentang soal-soal ekonomi, dibentangkan panjang lebar oleh Ibnu Khaldun di dalam bukunya "Muqaddimab" yang dibaginya dalam 33 pasal. Semuanya itu dapat disimpulkan pada enam bagian, sebagai berikut:

a. Pasal 1 mengenai terminologi dari kata-kata ekonomi, sebagaimana yang sudah dibahas di depan. ${ }^{42}$ Di antaranya, pembagian terminologi ekonomi pada dua kata, yaitu "rizqy" dan "kasab", di mana keduanya mengandung arti dan implikasi sendiri-sendiri. Dari dua kata ini pula Ibnu Khaldun memberikan satu pendapat bahwa ada usaha pribadi dan usaha publik. Dan usaha publik inilah yang dimaksudkan dengan usaha ekonomi yang sesungguhnya. ${ }^{43}$ Apabila kita terjemahkan dalam kehidupan modern saat ini, maka usaha publik ini identik dengan perusahaan-perusahaan yang bergerak dalam berbagai bidang, yang melibatkan banyak orang, tenaga dan juga melibatkan banyak tenaga ahli. Dalam dataran ini Ibnu Khaldun telah melangkahkan pikirannya jauh ke depan, dengan memprediksikan perusahaan umum tersebut.

b. Pasal 2 mengenai pembagian rencana-rencana ekonomi kepada dua golongan dengan macam-macam usahanya, yaitu golongan usaha yang natuurlijk langsung menjadi rencana ekonomi dan kedua golongan usaha

${ }^{41}$ Edwin RA. Seligman (ed.), Encyclopedia of The Social Sciences, Vol II, (New York: 1954), hlm. 416.

42 Abdurrahman Ibn Khaldun, op. cit., hlm. 381-382.

${ }^{43}$ Secara lengkap baca Muqaddimah, pasal 1, hlm. 380-382 
yang bukan natuurlijk menjadi rencana usaha ekonomi. ${ }^{44}$ Hal ini masih sangat terkait dengan pembahasan pasal sebelumnya. Keduanya terkait dan saling mempengaruhi.

c. Pasal 3 sampai dengan pasal 7 (5 pasal) menguraikan usaha-usaha yang bukan natuurlijk menjadi usaha ekonomi, dan juga uraian tentang faktor-faktor luaran yang ada pengaruhnya dalam ekonomi. ${ }^{45}$ Sebagai contoh yang riel diajukan oleh Ibnu Khaldun adalah faktor sosio politik sbagai linngkungan sosial politik yang melingkupi kehidupan sebuah masyarakat. Sehingga perilaku ekonomi akan terpengaruh oleh hal-hal tersebut dan hasil yang hendak diproduksipun sangat terpengaruh oleh apa yang dibutuhkan dalam kondisi politik tertentu.

d. Pasal 8 khusus mengenai soal pertanian. ${ }^{46}$ Pertanian dikatakan oleh Ibnu Khaldun sebagai usaha asli manusia untuk mencukupi kebutuhan hidup sehari-hari, terutama makan.

e. Pasal 9 sampai dengan pasal 15 (7 pasal) mengupas soal-soal perdagangan di dalam segala segi.47 Pada bagian ini dikemukakan pengertian perdagangan, yang oleh Ibnu Khaldun diterjemahkan dengan ilutrasi sebagai berikut: perdagangan "al-Tijarah" adalah perputaran pekerjaan dengan terjadinya pertumbuhan harta dengan pembelian secara seimbang, baik dengan harga yang murah maupun mahal, yang berlangsung secara keseharian, seperti jual beli kambing (hewan), pertanian, peternakan atau sandang yang menjadi keinginan (maksud) dari semua orang.

f. Pasal 16 sampai dengan pasal 33 (13 pasal) memberikan analisa tentang soal perusahaan di dalam segala bagiannya. 48 Prinsip-prinsip yang dikembangkan antara lain prinsip produksi, pelibatan jasmani dan pemikiran (rohani), pemenuhan kebutuhan umum dan untuk kepentingan orang banyak (kemakmuran bersama).

\footnotetext{
${ }^{44}$ Ibid., hlm. 384

${ }^{45}$ Ibid., hlm. 385-394.

46 Ibid., hlm. 394

${ }^{47}$ Ibid., hlm. 394-399

${ }^{48}$ Ibid.
} 
Soal-soal ekonoi di jaman kita sekarang jauh lebih luas dari apa yang diuraikan oleh Ibnu Khaldun pada 6 abad yang lampau itu. Bahkan semakin lama akan semakin bertambah banyak persoalan-persoalan yang berhubungan dengan dunia perekonomian. Hal itu terjadi karena semakin tumbuhnya perkembangan kemajuan pikiran dan kecerdasan manusia. Dan semakin banyaklah soal-soal prinsipil yang harus kita pecahkan dengan seksama dan sebaik-baiknya. Di dalam pertumbuhan yang terus meluas itu, akan semakin dalamlah pengakuan kita terhadap Ibnu Khaldun sebagai sang perintis jalan.

Ada cukup alasan bagi kita untuk berkata bahwa pandanganpandangan Ibnu Khaldun mempunyai pengaruh yang besar atas perkembangan teori-teori ekonomi pada jamannya yang pertama, jaman Renaissance di Eropa. Bukanlah hanya pendapat Aristoteles dan bukan pula semata-mata pendapat-pendapat dari gereja yang memberi pengaruh kepada pengarang-pengarang di masa itu. Tetapi sebagai pecinta bukubuku karangan Ibnu Khaldun, tidak pula sedikit pengaruh uraian philosof Islam ini tergambar di dalam teori-teori yang mereka tinggalkan.

\section{Al-Muqoddimah Ibnu Khaldun; Sumber Kebangunan Eropa}

Jika kita perhatikan akan uraian yang sangat luas dari ibnu Khaldun terhadap soal-soal pertanian (pasal 8 dari karyanya, Muqaddimab) dan soal perdagangan (pasal 9-15), kemudian dihubungkan dengan jaman renaissance di Eropa, maka tidaklah mengherankan bahwa dalam abad ke16, 17, dan 18 soal ekonomi di Eropa berpusat pada dua hal tersebut.

Dengan menyebutkan ini semuanya bukanlah dimaksudkan untuk mengatakan bahwa segala pendirian dan faham ekonomi yang bertentangan satu sama lain itu disetujui semuanya oleh Ibnu Khaldun. Maksud yang sebenarnya ialah ingin menegaskan sampai seberapa jauh pengaruh dasardasar ekonomi yang dikatakan oleh Ibnu Khaldun terhadap pendirian dan faham-faham ekonomi internasional. Karya ekonomi dari Ibnu Khaldun itu menjadi lampu di tengah-tengah kegelapan atau ibarat bintang di alam 
Pemikiran Ekonomi Bapak Ekonomi Islam; Ibnu Khaldun

cakrawala yang telah memberi pedoman bagi teori-teori ekonomi Eropa khususnya dan teori-teori internasional pada umumnya.

Menurut keterangan M. Luthfi Jum'ah dalam bukunya, "Tarikh Falsafatil Islam", dikatakan bahwa karya Ibnu Khaldun bagian ke-5 dari bukunya, Muqaddimah yang membahas tentang ilmu ekonomi pada umumnya telah menjdi dasar bagi Karl Marx sewaktu menulis bukunya, Das kapital. ${ }^{49}$

Namun perlu juga diketahui bahwa sebetulnya sebelum Ibnu Khaldun menulis karya-karyanya, sudah ada pujangga-pujangga Islam yang memecahkan soal politik ekonomi dan politik keuangan negara sesuai ajaran agama Islam. Mereka pun menuangkannya dalam karya yang sampai hari ini masih sangat berguna. Di antara karya beberapa pujangga tersebut antara lain:

a. Kitab al-Kharaj, karangan Abu Yusuf (wafat $182 \mathrm{H}$ ). Ia adalah Ketua Mahkamah Agung di jaman Khalifah Harun al-Rasyid. Tentang buku ini, Ali Abi al-Futuh, seorang ahli hukum berkebangsaan Mesir mengatakan, "Saya menjumpai di dalam buku kecil ini uraian-uraian yang sangat tinggi mutunya, yang sangat saya perlukan dan dengan istimewa akan menyalinnya dalam karangan saya ini, supaya segenap kaum muslimin terutama mereka yang besar minatnya kepada undangundang barat dapat meyakinkan bahwa ahli-ahli Islam purbakala tidak ketinggalan dalam segala soal untuk kita yang hidup di jaman belakangan ini. Mudah-mudahan timbullah hasrat mereka untuk mempelajari hukum syari'at dan kebudayaan Islam. Keduanya tidak bertentangan dengan jaman modern ini dan dengan kemajuan baru apabila dipahamkan dengan sebaik-baiknya dan dipelajari dengan akal yang cerdas." 50

b. Kitab al-Amwal, karangan Obeid Kasim bin Salim (154-224 H). Kitab ini membahas tentang kapital dan harta benda. Ia menguraikan segala soal kapital mulai dengan negara dan masyarakat sampai kepada kapital sebagai hak milik manusia.

${ }^{49}$ M. Lutfi Jum'ah, Tarikh falasifatil Islam, hlm. 104.

${ }^{50}$ Ali Abi el-Futuh, Al-Syariah al-Islamiyah wa al-Qawwaanïn al-Wadh'iyyah, hlm. 55 
Muhammad Luthfi Jum'ah, sebagaimana disampaikan di depan mensinyalir bahwa Karl Marx sewaktu menyusun bukunya, Das Kapital, berpedoman pada karangan Ibnu Khaldun. Sementara nama Das Kapital yang dipakai Karl Marx adalah salinan atau tiruan dari buku alAmwal karya Abu Obeid ini.

c. Kitab Siasatul Madaniyah (Politik Pembangunan Negara), karya Filosof Al-Farabi (260-330H). Buku ini khusus membicarakan tentang politik ekonomi, suatu ilmu yang sangat penting di jaman modern ini. Kitab ini termasuk satu dari delapan macam karya Al-Farabi dalam ilmu politik.

Inilah kenyataan-kenyataan yang harus kita lahirkan di dalam soal ekonomi ini supaya dijadikan pertimbangan yang lebih luas oleh para ahli pengetahuan, terutama para pakar ekonomi. Dan apa yang telah terurai di atas, paling tidak memberikan kontribusi positif terhadap bangunan teori perekonomian, yang akan turut menyertai naik turunnya perkembangan perekonomian umat di masa yang akan datang, di mana sejarah akan mencatat, bahwa teori ekonomi Ibnu Khaldun termasuk dalam jajaran ilmu yang dibutuhkan oleh umat.

\section{Penutup}

Sebagai bagian akhir dari makalah ini, ada sebuah ilustrasi yang mungkin dapat dikemukakan, bagaimana Ibnu Khaldun mampu membuka wacana ilmiah yang cerdas meskipun kehidupannya penuh dengan gejolak politik dan teror kekuasaan. Buku Muqaddimah yang ia tulis benar-benar telah mebuka mata para ilmuwan muslim maupun non muslim untuk mengkajinya. Karya ini diterjemahkan dalam banyak bahasa, dan dalam proses tersebut, Ibnu Khaldun akhirnya memperoleh atribut yang luar biasa, sebagai filosof sejarah, sejarawan, bapak sosiologi, geografer, ekonom, ilmuwan politik, dan lain-lain.

Khusus berkaitan dengan tema ekonomi, Ibnu Khaldun telah pula memprediksikan banyak hal yang akhirnya menjadi persoalan yang sampai pada dunia modern saat ini tetap mengemuka sebagai wacana yang tidak akan berhenti untuk dibicarakan. Sebagai contoh yang ia ajukan adalah kasus usaha 
Pemikiran Ekonomi Bapak Ekonomi Islam; Ibnu Khaldun

pribadi dan usaha publik, perlakuan dunia atas mata uang yang akhirnya mempunyai fungsi yang sangat fital dalam dunia ekonomi, dan lain-lain. Apa yang dikemukakan tersebut, murni berasal dari pemikiran cerdas Ibnu Khaldun. 


\section{DAFTAR PUSTAKA}

Abdullah Mustafa al-Maraghi, Fath al-Mubin fi Tabaqat al-Ushuliyyin, terj. Husein Muhammad, (Yogyakarta: LKPSM, 2001).

Abdurrahman Ibnu Khaldun, Muqaddimah Ibn Khaldun, Beirut: Dar al-Fikr, th.

Ahmad Syafi'I Ma'arif, Ibnu Khaldun dalam Pandangan Penulis Barat dan Timur, (Jakarta: Gema Insani Press, 1996).

A.J. Toynbee, A Study of History, 12 Jilid, London, Oxford Univercity Press, 1945, III.

Ali Abdul Wakhid Wafi, Ibnu Khaldun; Riwayat dan Karyanya, (Jakarta: PT. Grafika Pers, 1985).

Ali Abi el-Futuh, Al-Syari'ah al-Islamiyah wa al-Qawnaanïn al-Wadh'iyyah.

Ali Audah, Ibnu Khaldun, Sebuah Pengantar, (Jakarta: Pustaka Pelajar, 1982).

Bernard Lewis, et. al., The Encyclopedia of Islam, vol. VIII, (Leiden: E.J. Brill \& London: Luzac\&Co,1971).

Edwin RA. Seligman (ed.), Encyclopedia of The Social Sciences, Vol II, New York: 1954.

Fuad Baali, Society, State, and Urbanism; Ibnu Khaldun's Sociological Thought, New York: State University of New York Press, 1988.

Ismail R. Al-Faruqi, The Cultural Atlas of Islam, New York; Mac Millan Publicing Company, 1986.

Muhsin Mahdi, Ibnu Khaldun's Philosopby of History, (Chicago: The University of Chicago Press, 1971).

Mustaq Ahmad, Etika Bisnis dalam Islam, (Jakarta: Pustaka al-Kautsar,2001)

M. Lutfi Jum'ah, Tarikh falasifatil Islam.

Zainal Abidin Ahmad, Dasar-Dasar Ekonomi Islam, Jakarta: Bulan Bintang, 1979, hlm. 310

Volume IV/Edisi 1/Mei 2013 
Pemikiran Ekonomi Bapak. Ekonomi Islam; Ibnu Khaldun 